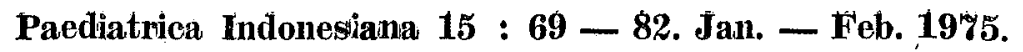

\title{
Why Package Child Care?
}

by

\author{
MAURICE KING
}

\begin{abstract}
The team responsible for developing this project starts by considering in detail exactly what workiers in Indonesia's health aantres aan usefully do (what intierventions they aan talke) in a particular service anea, in this case health centre child cane. These interventions are being incorponated into a complete, problem oriented illustnated, basic language tiext of health centre child came. This text is to be supported by a variety of other components which includle three matchjod sets of multiple choice questions covering its intime field, sichediules of assiessing the pmactianl performiance of procedunes, equipment lists, methodls of quality control, currioula and tiaching aids, as well as guidiance on the rontime audministriation of this services provided and their initial introduction inito a new area. All these components fit tagether to form a health a ane paxalagie which is defined as "ian integnatiel set of compoments for thle improvement of health care in a defined service larea and under specific socio-economic conditions". The hypothesis behind the comcept is that the combined leffect of the components is mone than imenely addiditive.
\end{abstract}

Received 12th. August, 1974.

Presented at the Third National Indonesian Paediatric Congress, Surabaya, July $1-6,1974$. 
The child care package. One of the developing world's most urgent needs is an improvement in the quality of its child care services. This is needied not only because the loss of each child is a tragedy to himself and his family, but also because mothers will not limit their families until they can be sure that their children are going to survilve. Paradoxically therefore, improved child care may be one of the keys to population restraint. However, the improvement of child care on a country-wide scale is not easy to achieve. We endeavour, to show here that, besides the many intractable social and economic constraints upon improvement, there lis an important technical one which should be possible to minimise comparatively easily, and with good results under certain circumstances.

The effective administration of the child care services of a country rests among other things, upon a very large number of dietailed technical decisions, many of which are very time consuming and some of which require opportunities for communication, such as access to the Iiterature, or to the knowledge of other people. They include such de cisions as these. What should be our objectives in teaching child care to midwives? What is the best kind of infants iron mixture to put into the medical stores list? What criteria can we use to audit the quality of child care in our clinics? The right answers to these questions depend upon a compound of skilled and interested decilsion making ability, the availability of the large quantity of time needed to make some of them effectively, and also upon the necessary opportunities for communication. The compound of these factors is at a great premilum in the developing world, and lack of it imposes a severe consitraint on improvement of services for child care.

The means proposed here to mitigate this constraint follow from the writer's previous work in Africa and from a project in which he ils taking part at the Lembaga Kesehatan $\mathrm{Na}$ sional in Surabaya.

Consider, for erample, the task before the overworked MCH specialist of a develloping country when he tries to up-grade child care in the clinics for which he is responsible. If he lis to do this as perfectly as can be, he must first decide exactly what dilseases his child care workers are to diagnose, how a child is to be examined and treaited and with what. From this must follow detailed drug and equipment lists. He must then make out a lilst of behaviourally defined educational objectives for his workers, and write a manual in easiIy comprehensible language, for there is unlikely to be a suitable one available. After this our MCH specialist must see that curricula are devised together with teaching aids and examinations for the trainees as well as methods of supervising 
and auditing the quality what they do. Finally, he must establish the best ways of organising in-service training for his staff, many of whom will have been imperfectly trained a long time ago.

All this is going to require much interested skill and time, and it ols the comparative scarcity of this which is so limiting. Sometimes, although the necessary skill may be present, it is not availlable, in that the tasks we have listed are not considered worthy of attention, even though they all contribute to the standard of care provided. Hence some of the reasons why so complete a range of tasks has never been completed and why the child care services of the developing countries are as they are. However, once the required time and skill have been expended for one country, much of the product of it, is transferable elsewhere, and the same 'chilld care package' could be used to great advantage in all other countries of the same socio-economic pattern, of which there are at least fiffity, with the need for only minor modification and translation. Needlless to say, the decistion to use such a package is a national responsibility, but it would be useful to have a choice of some internationally availlable prototypes for adapitation. In the process of such adaptation a package would become a national possessión.

2. A package defined. Such then is the rationale for a health care package which is defined as an integrated set of components for the improvement of health care under specific socio-economic conditions'.

The construction of a package is an alttempt to define and isolate a particular service area, such as health centre child care, and then to do everything technilcally necessary to improve services within it. The term 'service area' is chosen deliberately as including fumction, level and situation. Needless to say this ilsoliation is largely artificial, because most service areas have links with most others, but it is only posisible to do everything technically necessary in a field when its boundary has been carefully defined, so that great attention can be given to a limited area at a time.

The boundaries of a package determine its links or interfaces with neighbouring packages, and with the rest of a service. Thuis a child care package must be closely related to one for nuitriltion, and it should also interface with one for laborato. ry methods. Such an arrangement of packages is shown in Figure 1 . Because it might be convenient to consider maternity care and family planning as a single service area for package purposes, they have been shown together in this figure. $\mathrm{Be}$ cause the isolation of a service area can never be completely tidy, some overlap may be necessary, in the sense that a worker in child care 
should know how to make use of a simple laboratory.

After a service area has been chosen and defined the next crittical step is ito consider in detail every intervention (action) which is to be taken within it, complete, where necessary, to the last physical sign to be looked for, or the exact specification of every mixture to be prescribed. Because these interventions are' most usefully considered in terms of behaviourally defined educationali objectives, they are linked together in Figure 2.

A detailed manual has then to be written round these objectives, so that they are described completely. The other components which have also to be designed include equipment lists, curricula, teaching aids, examinations for the trainee worker, and quality control methods for auditing his subsequent performance in service. A package may also need to include procedures for recording and reporting, guidance for its routine administration, and an account of the administrative steps needed to introduce it into a district for the first time.

The purpase of a package stems from the postulate that, although its individual components are likely to be useful by themselves, their combined effect is likely to be more than merely additive. Thus, a set of equipment for child care, or a manual, are of little use alone, but used together they may be very valuable. Multiple choice questions, for example, may greatly stimulate the reading of a manual. Great emphasis is placed on the components of a package: being integrated and complete. Thus, if a particular item of equipment is described in a manual, it must be in a government's medical atores list. The components have also got to be complete in the sense that a manual on elementary child care must include all that a junior health worker needs to know in this field.

From amother point of view, a package is an attempt to deal, not, with the isolated fragments from which services are constmucted technically, such as equipment lists or manuals, but with a larger unit in which they are all integrated. Were not the word 'system' even more overworked than that of 'package', it might have been used instead. As with a system, a package is no less an aggregatte of dynamic elements that are in some way interconnected and interdependant.

Although several of the components of a package can be grouped under the heading of 'educational technology', the concept of the package is wider than this, for it is as concerned with selecting and developing what to teach, as how to teach it, and with the funationing of a service as well as forming manpower for it. The idea of the package will also be seen to embrace those of 
standard technology; and standard equipment and methods. Also, it is more than merelly a kit of equipment, or a certain mix of services, such as family planning and maternity care.

It might be said that the package is a new name for an old didea. It would be more true to say that insistence on the full development and integration of the components of a package represents the further progress of an existing trend. 'Package making' is the completion and fitting together of the numerous technical fragments needed to develop a service, mosit of which already exist somewhere. It is a way of applying existing knowledge. Esssentially, packages are assembled know - how', but when they are applied, it may be necessary to supply some hardware with them.

3. What shall we pack? Several factors determine whether a particular service area might be usefully be 'packaged' in the way described.

How severe is the technical constraint in the country in which the package is to be used? This is shown by lack of the various components. Thus a technician with plenty of books and telephone access to equipment suippliers has no need for an entire package for his laboratory, although he may be able to make use of smaller packages, or systems, such as those for the 'Autoanalyser' for example On the same reasoning packages are not likely to be needed in well staffed medical schools, or perhaps in the industrial countries generally, where there is such an abundance of skills, and such a choice of overlapping 'components', even if they are not necessary integrated with one another.

In many developing countries it is hardly possible to overstate the severity of the technical constraint, and the almost total absence of most components. In the world as a whole it is probable that most auxilianies are still taught by dictaltion, for lack of anything they can read, let alone a carefully, 'package manual with its associated teaching aids.

How limiting is the technical constraint in the provision of medical care? Economic and particularly social constraints may be so serious that even the 'successful' introduction of a package may have littile effect on standards of care, and thus on morbidity and mortality. Thus, a health centre child care package might be highly successful in increasing the abilitity of staff to care for chilldren; yet if the administrative system cannot supply the necessary drugs, there may be little improvement in levels of care. The value of introducing such a package may thus be severely mitigated, if the supply system is not improved at the same time.

How many components are needed? A package only exists where there are several components together, so that, if there is no need for 
muiltipile integrated components, there is no need for a package. For example a manual might be useful in such a broad servilce area as, say, 'public heaith administration', but it is difficult to see what components might be integrated with it to make a package.

How readily can the service area be defined and isolated? The sharper the boundaries of a service area, the easier it will be to package. For example, the health centre laborato. ry isolates and packs very well, child care in, the health centre is more difficult to isolate, while 'public health nursing' or 'nursing education "could ondy be isolated with great difficuity. The dissection of a service area into smaller ones proceeds more easilly along some planes than others. The laboratory, for example, separates without difficulty from the rest of the work of a health centre, but it is less easy to separate nutriltion from child care, or the care of a mother from that of her child.

How many units of the package are going to be needed? Thils depends on the extent to which they can be standardised for different countries, and the frequency with which they are required in a health service. Laboratory services for example lend themselves to standardisation much more readily than those for nutrition. Packages for health centres are requitred in much larger numbers than those for medical stores.
In summary then, it is at the periphery of the health services of the developing countries, especially where auxiliaries are concerned, that a series of interfacing packages would be so valuable. The basilc health services could perhaps usefulliy incorporate packages for half a dozen service areas, but it might not be practicable to package everything they do.

4. What is the best size for a package? It would be theoretically possible to construct a very large package covering the entire work of a health centre, to make one for MCH only, to consider child care alone or to make many small packages for single procedures, such as the use of the weight chart. Big packages would be insufficiently flexible, and many small ones difficult to relate to one another. Even a single complete package for $\mathrm{MCH}$ would be too big to be made without greart difficulty, and at is a service area the size of, say, 'child care in the health centre', that will probably be found to be the most useful. Because the necessary interventions have to be described in manuals, the best size for one of these is an important factor in determining the optimum size for a package.

The proposed use of a package als also importanit in determining its boundaries and its size. For example, it his useful to put the more general aspects of nutrition into a package 
that can be used both by health workers and by those in other sectors, and to confine its more clinical as pects to one for heallh workens onily.

5. Packages and workers. In theory at least it is customary in forming medical manpower to consider a caitegory of worker, to write a job description for him, and then to go on to educational objectives and curricula. This process is bedevilled by the great difficulty of writing useful job descripitions when a worker's role may vary so greattly in different situations, by the many kinds of worker in some countries, and by the failure to integrate a job descria ption with the components we have described here It is perháps for these reasons that such a process is so seldom completed satisfactorily.

The 'package' method takes a servil ce area, such as child care in the health centre, and provides the techa nical basis for training a variety of workers in it. The educational cont? ponents of such a package could be used for training monovalent wor kers in this field, as well as polywa lent workers such as medical assist tants or mildwives. They would be of interest to medical students, and might even be used by community volunteers. Conversely; the trainfing of a polyvalent worker, wuch aswa midwife, might include packageotided midwivery, nutrition, family sofan

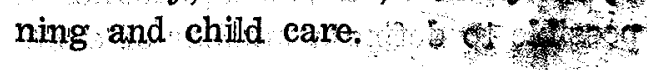

6. Manuals. Much success in me-dicine depends on careful attention to detail, and manualls come second only to personal instruction in their potential to collect and transmit this. Hence the reason why there has recently been such an increase of interest in them.

The heart of a package is its manuals, and these must be complete, because an auxiliary is unlikely to own any other text. The junior staff need one kind of manual, for this defines what they shall do, and shows them how to do it. If there is only a little to be said to their seniors, this can be done by addressing a flinal chapter to them. But, where there is much to be said, as there should be in, in well, developed packa-

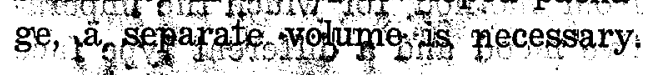
This becomes a teachers and administrators guide'- or 'companion to the package fand contrins such things as equipment lists, quality control proeedures, guidance on tea. ching methods, practical exercises, abd stanidard sets of multiple choice questions, as well as the scones that ane expected from then.

Hecause it is so necessary for a manual ito stbe supported by other componientss, the unpackanged manual' pepresents a negleoted opportunity, and there is even a case for saying 梦fat manuails should no longer be whittem for auxillaries unless they are part of a carefully designed pacHage. The 'unpackaged equipment 
list' is on occasion a similiar anach. ronism.

Manuals for auxiliaries need to be in a style that is as close as possible to 'basic English', or ots equivalent in other languages. Technical terms have to be explained where necessary, but it is not these "that defeat the reader so much as the size of the ordinary vocabullary of say, English, French or Spanish, with their wide range of near synonyms. Technical terms apart, it is possibile to work with as small a vocabulary as 800 words. Other important matters of style include the need for numerous illustrations, which should, if necessary, be in cook-strip form, and the careful distinction of 'discussion' from 'method' for which the imperative mood and a different type face is required.

Because the effectiveness of a package depends so much on the ability of junior staff to read and use its manuals, the quality of their style and language cannot be sufficiently stressed. For brevity, efficiency, and the ease with which it adapts to being written 'basic' English is unusual as a medium for technical communication. For this reason it may be that a manual which was originally written in basic English, anid is understandiable to an Anglothone dresser, may not be usable by anyone less educated than a registered midwife when it has been translated into another language. The wider use of a package may thus be severely restricted by the limited linguistic potential of some languages, and by the difficulty of obtaining sufficiently painstaking and scholanly translations into them.

It is commonly thought that manuals have to be specific to a single grade of worker only. But this is not invariably so, and by carefull attention to style and language it is possible to cover such a wide readership that a text becomes required reading both for postgraduate physicians and dressers (King, 1973).

7. Indices for evaluation. The ulitimate purpose of a package is to reduce morbidity and mortality, but to evaluate one routinely by its ability to do this would be both expensive and laborious, even where it was possible. Because of this limitation, the only way to assess the quality of a package is to measuine its effect on improving the quality of a worker's performance. This is more difficult with some packages than with others. For example, the quality of a blood film, or the ability to examine a pathological specimen can be assessed comparatively easily, but clinical packages are more difficult. Never. theless, to define something is to go a long way towards being able to measure it, and the complete definition of a pattern of clinical practice in the form of a package makes it possible to define a number of expli- 
cit criteria that can be used to audit the process of caring for a patient.

For example, if a package is recognised as embodying a nationally accepted standard of 'good medicine' for its particular circumstances, then the roultine performance of a clinic or a worker can be compared with this standard and an index obtained for quality of care. Thus; if caring for a child with fever should include such steps as asking his mother how long he has had his fever, or examining his ears, then whether or not these steps are followed can be used to derive the index. Unfortunately, most of the conventional olinical wisdom has of necessity to be taken for granted in constructing a package, and it is not possible to investigate more than a few critical areas of clinic practice.

Some variables which relate, however indireotly, to the quality of care, such as the proportion of the list of essential supplies which are actually available in an MCH clinic; can be included in an index that can be roultinely reported. But, those which relate to a clinical interview have to be obtained by a trained observer who bases his assessment on whether the prescribed steps for dealing with a problem are followed or not. Such measures are admittedly crude, but current practice leaves so much to be desired, that they promise to be useful.

If good practice depends on the application of a carefully defined body of knowledge, then the grasp of this knowledge is likely to influenice practice. To test this a package should contain matched sets of multiple choice questions covering its entire field.

One of the most important varia bles in regard to some packages is, who benefits from them? With child care, for example, it is possible to incorporate a 'tracer' in the package, in the form of a weight chart that a child's mother keeps, the assumption being that a child possessing $a$ weight chant has access to the rest of the package.

The careful definition of a pattern of child care in the form of a package also makes it possible to measure other variables which are useful adminisitratively, suoh as norms for cost per chilld seen, and output per worker.

8. Development and research. No detail is insignificant if a package is for mass use, and this is especially important in the improvement of existing technology, hence the upwardly pointing arrow in Figure 2.

Thus, if it would be useful to have a weighing scale for children with graduations on it that matched the weight chart used in the clinics, then some manufacturer must be persuaded to make them. If it would be useful to have mixtures for children available as dry powders, then these too must be made. 
The large scale use of a package also justified such sophisticated but marginal activities as the linguistic analysis of a text, or the development of a special computer program to extract : indices for evaluation from the data contained on a clinic's weight chart.

Another benefit to be derived from the assembly of a package is that it makes the gaps in a technical field more obvious. One that has recently come to light is that there appears to be no detailed account in English, or perhaps in any other language, of how an auxiliary should examine a child!

The ordered assembly of existing knowledge also highlights the gaps in what we know. Thus, while there is no need, for example, to test the efficiency of polio vaccine, it would be useful to assess the place of myringotomy in clinic practice, and to evaluate the different ways of managing skin sepsis.

9. The achievement of change. The adopition of a package might gradually increase the quality of care by improving the competence of incoming staff whose training has been based upon it. But it is less easy to see how a package might radically improve services by changing the practice of existing staff who have long got into bad ways. Service wide experiments have yet to be undertaken, but it is expected that several factors are likely to be important in using a package to induce change.

The first is that every action expected of a package must be possibile. It is postulated that for every action which is not possible, several others which are possible will not be done either. Thus if routine immunisation is expected; then a refrigera. tor in which to store vaccines must, if necessary be supplied as part of the package. The deficiencies of many supply systems make this a very exacting precondition.

Maximum use must foe made of the ability of various components to support one another. If new equipment is needed, then this must be suppliled when a package is introduced. Not only must improved supplies support new actions, but a reporting system which contains an index of quality of care, however imperfect, must be used to support it also.

A package must be most effective in inducing change if introduced inito a idistrict completely all at once, accompanied by the necessary meetings and refresher courses, rather than piecemeall.

Each health worker must own his manuals, which must be of hilgh quality, both of content and presentation.

If it is not the custom to do any additional work such as r attend or give a refresher course; withont a financial incentive, then these must 
also accompany the introduction of a package.

It remains to be seen how high a level of input in terms of equipment, drugs, manuals, teaching aids and incentives etc. is necessary to effect a significant change in quality of care under particular circumstances.

The relationship between input and change may not be linear, and there may be a threshold value.

10. Packages and planning. Much current health planning ends when, say, medical assistants and health centres have been counted, costed, and projected for into the future.

Much of its weakness lies precisely in that it goes no further. The defjnition of the kinds of package these staff are going to use enables the health planner to know more exactly what they are going to be able to do.

Packages can thus be likened to the 'fingers on the end of the health planning arm', or to the bricks from which health services are ultimately built. They define much of the detailed 'nitty gritty' of which these services finally consist, and take health planning down to the level of the laboratory bench, the operating table, the healith education lesson, or just how an auxiliary should examine a child. They thus make it possible to plan thealth services more precisely, and potentially define them. down to the smallest detaill. Indeed, the test of a package is likelly to be the quality of its detail.

Health planning has shortcomings enough on the macro scale. How should resources be spent? or, what cadres of staff should be trained? Yet services are neglected and fail more significantly on the micro scale. What should an assistant nurse mildwife be taught? What size of polythene tube should be issued to the clinilc? How should child care be reported? These are the very stuff of completed packages, and in the developing countries more concentration on the detaills of the micro-level is a most necessary balance to the generalities of the macro scale. This is particularly necessary in public health courses, because it is at this level that most partilicipants will potentially be able to do something.

Health services are not easy to define. There are 'health centre services', 'well and sick child clinics' and 'under fives clinics' but it is not easy to be sure exactly what they do. The complete specification of a child welfare clinic, 'for example, down to the last tablet and educational objective, combined with its various measurement inidices, may have some useful secondary effects in heailth planning. By making child welfare much more tangible and measurable, it may encourage governments to provide it, donor countriles to aid iit, and 'perhaps even consumers to demand it. 
11. The place of the package. on of basic know how, they set educational itechnology in a logical fraOne thing is certain-packages are mework, and they are 'grass-roots' no panacea for bad services. It is equalily certain that nothing else is either. They are but one approach among many to good services. $\mathrm{Ne}$ verthelless packages are nicely complementary ito the present techniques of macro-planning, they munimise an important constraint, they are directly concerned with the replicatiand 'poverty-focussed'. They also provide an exact way of defining $\mathrm{mi}$ nimum levels of personai health care, and even perhaps eventually of human rights to it (King, 1973). Besides being comparatively cheap to design, they may also in the right cilrcumstances, prove to be highly effective.

\section{REFERENCES}

1. KING, M.H: A Medical Laboratory for Developing Countries (Oxford University Press, London 1973).

2. KING, M.H.; KING FELICITY; M.A.; MORLEY, D.; BURGESS H.L and
BURGESS, ANN, P. : Nutrition for Developing Countries (Oxford Univer. sity Press, Nairobi 1973).

3. KING, M.H.: Ciba symposium, $\mathrm{Hu}$ man Rights in Health' 1973. 